\title{
Risk factors for sub-therapeutic serum concentrations of magnesium sulfate in severe preeclampsia of Chinese patients
}

\author{
Jingjing Li', Lian Tang ${ }^{1}$, Ruiheng Tang ${ }^{2}$, Lan Peng ${ }^{3}$, Liqiang Chai ${ }^{3}$, Liping Zhu ${ }^{3}$ and Yanxia Yu ${ }^{1 *}$ (D
}

\begin{abstract}
Background: Magnesium sulfate $\left(\mathrm{MgSO}_{4}\right)$ is the standard drug for eclampsia prophylaxis and treatment. In China, the effective therapeutic serum magnesium level is $1.8-3.0 \mathrm{mmol} / \mathrm{L}$. There is little information on how to achieve and maintain effective therapeutic concentrations. This study aimed to investigate risk factors for sub-therapeutic serum concentrations of $\mathrm{MgSO}_{4}$ in patients with severe preeclampsia.
\end{abstract}

Methods: Patients with severe preeclampsia who received $\mathrm{MgSO}_{4}$ intravenous infusion were retrospectively reviewed. The maternal demographic characteristics, regimens for the administration of $\mathrm{MgSO}_{4}$, and lab test results of patients were collected. Multivariate logistic regression analysis and receiver operating characteristic (ROC) curve analysis were conducted for the risk factors influencing the serum magnesium concentration.

Results: A total of 93 patients with severe preeclampsia were included in the study. 52 (55.91\%) patients did not attain therapeutic serum magnesium levels. A multivariate logistic regression analysis identified creatinine clearance (Ccr), whether the loading dose was given, and measurement time of serum magnesium concentration (referring to the time from start of MgSO4 infusion to blood draw for serum sampling) as independent risk factors for subtherapeutic serum magnesium concentration $(P<0.05)$. ROC curve analysis indicated that the continuous variable $\mathrm{Ccr}$ had a significant predictive value for the serum magnesium concentration, which resulted in a cutoff point of $133 \mathrm{~mL} / \mathrm{min}$; while measurement time had limited predictive value, with cutoff point of $2.375 \mathrm{~h}$.

Conclusions: $\mathrm{Ccr}$, whether the loading dose was given, and measurement time were independent risk factors for sub-therapeutic serum magnesium concentration. A loading dose of $\mathrm{MgSO}_{4}$ everytime before the maintenance dose, as well as the duration of $\mathrm{MgSO} 4$ maintenance dose of more than $2.375 \mathrm{~h}$ are recommended for all the patients with severe PE. Routine evaluation of serum magnesium levels is a recommended practice for women with severe PE and whose $\mathrm{Ccr}$ is $\geq 133 \mathrm{~mL} / \mathrm{min}$.

Keywords: Severe preeclampsia, Magnesium sulfate, Risk factors, Receiver operating characteristic curve, Logistic regression

\footnotetext{
*Correspondence: yuyxsz@163.com

'Department of Pharmacy, The Affiliated Suzhou Hospital of Nanjing Medical University, Suzhou Municipal Hospital, Suzhou 215002, Jiangsu, China

Full list of author information is available at the end of the article
} 


\section{Background}

Preeclampsia (PE) is a multi-system disorder of widespread vascular endothelial malfunction and vasospasm, characterized by elevation of blood pressure after 20 weeks of gestation in a formerly normotensive woman, with proteinuria, or in the absence of proteinuria, newonset hypertension with the new onset of end-organ dysfunction, affecting 6-8\% of all pregnancies [1]. Adverse outcomes tend to occur more frequently in severe cases of PE and eclampsia [2].

Magnesium sulfate $\left(\mathrm{MgSO}_{4}\right)$ is the preferred pharmacological intervention to treat severe PE because it can prevent the recurrent seizures of eclampsia [2, 3]. Total dose of $\mathrm{MgSO}_{4}$ reported worldwide for the treatment of $\mathrm{PE}$ and eclampsia ranged from $2 \mathrm{~g} / 24 \mathrm{~h}$ to $54 \mathrm{~g} / 24 \mathrm{~h}$ [48]. Serum magnesium level of $2.0-3.5 \mathrm{mmol} / \mathrm{L}$ is considered therapeutic by several authors [8-14]. While in China, optimal control of convulsions is thought to be most effective with therapeutic serum magnesium level at $1.8-3.0 \mathrm{mmol} / \mathrm{L}$. [4] Sub-therapeutic serum magnesium level may increase risk for eclamptic seizures [9]. On the other hand, $\mathrm{MgSO}_{4}$ overdose may result in serious toxicities, including maternal loss of the patellar reflex, respiratory paralysis, cardiac conduction and cardiac arrest $[10,15]$. To date, there is little information on whether serum magnesium level can reach the effective therapeutic concentration and the influencing factors in patients with severe PE in China. In the present study, the clinical data of 93 patients with severe $\mathrm{PE}$ treated with $\mathrm{MgSO}_{4}$ were analyzed retrospectively to explore the risk factors for serum magnesium not reaching the therapeutic concentration.

\section{Methods}

\section{Study population}

The ethics committee of Suzhou Municipal Hospital approved our study protocol (K2017037). This was a retrospective analysis of electronic medical records of all women with severe PE admitted to our institution for delivery who received IV $\mathrm{MgSO}_{4}$ for seizure prophylaxis from January 2016 to December 2018. Verbal informed consent was obtained from all participants by telephone. Inclusion criteria were: (1) singleton pregnancy, (2) aged 18-45 years, (3) the baseline serum magnesium concentrations were measured before IV infusion of $\mathrm{MgSO}_{4}$, and (4) serum magnesium levels were measured during IV infusion of a maintenance dose. We excluded patients with multifetal pregnancies or other pregnancy complications, such as hepatic diseases, kidney diseases, etc. Diagnostic criteria of PE include the development of hypertension after 20 weeks of gestation in women with previously normal blood pressure, and proteinuria or in the absence of proteinuria, new-onset hypertension with new onset of thrombocytopenia, renal insufficiency, impaired liver function, pulmonary edema, cerebral or visual symptoms. The diagnostic standards of hypertension shall be in accordance with a systolic blood pressure of $140 \mathrm{mmHg}$ or higher, or a diastolic blood pressure of $90 \mathrm{mmHg}$ or higher on two occasions at least $4 \mathrm{~h}$ apart. Proteinuria is defined as the excretion of $0.3 \mathrm{~g}$ or more of protein in a 24-h urine collection. Alternatively, a protein/creatinine ratio of at least 0.3 (each measured as $\mathrm{mg} / \mathrm{dL}$ ) or dipstick test reading of $1+$ is used. PE is diagnosed as severe based on classic criteria of blood pressures greater than or equal to $160 / 110 \mathrm{mmHg}$ and proteinuria greater than or equal to dipstick reading of $2+$. Other notable parameters symptoms are: persistent headache, visual disturbances, epigastric pain, intrauterine growth retardation and impaired hepatic and renal function tests $[3,4]$.

The patients with serum magnesium level 1.8 to 3.0 $\mathrm{mmol} / \mathrm{L}$ after IV infusion of $\mathrm{MgSO}_{4}$ were assigned to Standard group, and those with serum magnesium level $<1.8 \mathrm{mmol} / \mathrm{L}$ were assigned to Sub-standard group. We collected data on maternal age, gestational age, height and weight, creatinine clearance (Ccr), alanine aminotransferase (ALT), aspartate aminotransferase (AST), albumin, baseline serum magnesium concentrations, whether the loading dose was given, and measurement time (referring to the time from start of $\mathrm{MgSO}_{4}$ infusion to blood draw for serum sampling.). The $\mathrm{Ccr}$ was calculated from the serum creatinine by the Cockcroft-Gault equation: $\operatorname{Ccr}=\frac{(140-\text { Age }) \times \text { body weight }[\mathrm{kg}]}{\mathrm{Cr}[\mathrm{mg} / \mathrm{dL}] \times 72}$, where $\mathrm{Cr}$ was the serum creatinine. For women, the formula requires multiplication by 0.85 .

\section{IV administration of $\mathrm{MgSO}_{4}$}

A $5 \mathrm{~g}$ IV loading dose was or was not administered over $30 \mathrm{~min}$, followed by a maintenance dose of $1.5 \mathrm{~g} / \mathrm{h}$ for $10 \mathrm{~h}$ using an infusion pump (Terufusion infusion pump TE-135, Terumo Corporation, Tokyo, Japan).

\section{Measurement of magnesium level in the serum}

Serum magnesium level was measured by $2 \mathrm{~mL}$ of venous blood sampling, which were collected into serum separator tubes (Becton Dickinson Franklin Lakes, NJ, USA). The blood samples were centrifuged at $3000 \mathrm{rpm}$ for $5 \mathrm{~min}$ within $30 \mathrm{~min}$ of collection. Automatic biochemical analyzer (HITACHI 7600, Tokyo, Japan) was used to measure total magnesium, and serum magnesium concentrations of $1.8-3.0 \mathrm{mmol} / \mathrm{L}$ were considered therapeutic window for severe PE.

\section{Statistical analysis}

On-admission factors, including age, height, weight, body mass index (BMI), gestational age, creatinine clearance (Ccr), alanine aminotransferase (ALT), aspartate 
aminotransferase (AST), albumin, baseline serum magnesium concentrations, measurement time, whether the loading dose was given, were expressed as number (\%), mean \pm standard deviation (SD) or median (quartile). Chi-square test was used in comparison of the parameter of whether the loading dose was given between the Standard group and Sub-standard group. For quantitative variables, the Kolmogorov-Smirnov test was used in the normality test. The age, weight, BMI, Ccr, ALT, AST, albumin, baseline serum magnesium concentrations, measurement time were not normally distributed, while the height and gestational age were with normal distribution. The Mann-Whitney $U$ test was used to compare the parameters without normal distribution. The T-test was used in comparion of the data normally distributed between the Standard group and Sub-standard group. Univariate and multivariate analyses were performed to explore potential risk factors for subtherapeutic blood magnesium concentration. Variables with a $P$-value $<0.1$ on the univariate analysis were included in a multivariate logistic regression analysis. The weight, BMI, Ccr, albumin, measurement time and whether the loading dose was given were included into the multivariate logistic regression model to explore independent risk factors associated with sub-therapeutic blood magnesium concentration. We also calculated the odds ratio (OR) and 95\% confidence intervals (CI). The area under ROC curve and the cut-off values were evaluated. Statistical analysis was proceeded using SPSS version 22.0 (RRID: SCR_002865). Differences with a $P$ value $<0.05$ were considered statistically significant.

\section{Results}

The study included ninety-three women with severe PE who received IV infusion of $\mathrm{MgSO}_{4}$ for seizure prophylaxis. Among these patients, there were 41 (44.09\%) and 52 (55.91\%) patients who did (Standard group) and did not (Sub-standard group) attain therapeutic serum magnesium levels. No one had the occurrence of seizure in the two groups studied during hospitalization. Table 1 shows the maternal demographic characteristics, lab test results, the regimens for the administration of $\mathrm{MgSO}_{4}$, and serum magnesium levels of the patients in the two groups. The Standard group and Sub-standard group showed no significant difference in age (28.00 vs. 31.00 , $P=0.078$ ), height (159.4 vs. $160.8, P=0.109)$, BMI (27.79 vs.29.40, $P=0.090)$, gestational age (31.96 vs. $32.48, P=$ $0.285)$, ALT (28.00 vs. $24.50, P=0.200)$, albumin (27.2 vs. 28.1, $P=0.084)$, and whether the loading dose was given (18 vs. $14, P=0.087$ ). The baseline serum magnesium concentrations were similar in both groups $(0.76$ vs. $0.73, P>0.05$ ). The median (quartile) serum magnesium concentration of women in Standard group was $2.08(1.89,2.25)$, while it was $1.39(1.21,1.61)$ for Substandard group. Women in Standard group had significantly lower weight (70.00 vs. $71.80, P=0.048)$, lower $\mathrm{Ccr}$ (127 vs.162, $P=0.000)$, higher AST (30.00 vs. $26.50, P=$ 0.007 ), and higher measurement time (5.00 vs. $1.00, P=$ $0.013)$ than women in Sub-standard group $(P<0.05)$.

Through univariate analysis, we found that weight, BMI, Ccr, albumin, measurement time, and whether the loading dose was given were statistically significant risk factors for sub-therapeutic blood magnesium

Table 1 Maternal demographic characteristics and serum magnesium levels of the patients in two groups

\begin{tabular}{|c|c|c|c|}
\hline Variables & $\begin{array}{l}\text { Standard group } \\
(N=41)\end{array}$ & $\begin{array}{l}\text { Sub-standard group } \\
(N=52)\end{array}$ & $P$-value \\
\hline Age (years) & $28.00(26.00,33.50)$ & $31.00(28.25,35.00)$ & 0.078 \\
\hline Height (cm) & $159.4 \pm 4.4$ & $160.8 \pm 5.4$ & 0.109 \\
\hline Weight (kg) & $70.00(65.00,74.65)$ & $71.80(67.08,84.50)$ & 0.048 \\
\hline BMI $\left(\mathrm{kg} / \mathrm{m}^{2}\right)$ & $27.79(25.64,29.43)$ & $29.40(25.67,31.63)$ & 0.090 \\
\hline Gestational age (weeks) & $31.96 \pm 3.65$ & $32.48 \pm 4.13$ & 0.285 \\
\hline $\mathrm{Ccr}(\mathrm{mL} / \mathrm{min})$ & $127(97,155)$ & $162(132,189)$ & 0.000 \\
\hline $\mathrm{ALT}(\mathrm{U} / \mathrm{L})$ & $28.00(21.50,43.00)$ & $24.50(20.00,37.50)$ & 0.200 \\
\hline AST (U/L) & $30.00(22.00,35.50)$ & $26.50(23.00,36.50)$ & 0.007 \\
\hline Albumin (g/L) & $27.2(24.6,30.2)$ & $28.1(26.5,31.8)$ & 0.084 \\
\hline Baseline serum magnesium concentrations ( $\mathrm{mmol} / \mathrm{L}$ ) & $0.76(0.71,0.84)$ & $0.73(0.68,0.81)$ & 0.094 \\
\hline Measurement time (h) & $5.00(1.00,7.00)$ & $1.00(0.50,6.00)$ & 0.013 \\
\hline Loading dose $5 \mathrm{~g}$ & & & 0.087 \\
\hline Given (n) & 18 (43.90\%) & 14 (26.92\%) & \\
\hline Not given $(n)$ & $23(56.10 \%)$ & 38 (73.08\%) & \\
\hline
\end{tabular}

BMI Body mass index, Ccr Creatinine clearance, ALT Alanine aminotransferase, AST Aspartate aminotransferase 
Table 2 The results of univariate analysis for risk factors associated with sub-therapeutic blood magnesium concentration

\begin{tabular}{llll}
\hline Variables & OR & 95\%Cl & P-value \\
\hline Age & 1.066 & $0.983-1.156$ & 0.121 \\
Height & 1.059 & $0.973-1.152$ & 0.184 \\
Weight & 1.047 & $1.006-1.090$ & $0.024^{*}$ \\
BMI & 1.117 & $0.998-1.249$ & $0.054^{*}$ \\
Gestational age & 1.035 & $0.931-1.150$ & 0.524 \\
CCr & 1.017 & $1.007-1.028$ & $0.001^{*}$ \\
ALT & 0.989 & $0.973-1.005$ & 0.176 \\
AST & 0.994 & $0.977-1.010$ & 0.449 \\
Albumin & 1.099 & $0.995-1.214$ & $0.062^{*}$ \\
Maintenance dose & 1.237 & $0.452-3.385$ & 0.678 \\
Measurement time & 0.850 & $0.742-0.975$ & $0.020^{*}$ \\
Whether the loading dose was given & 0.471 & $0.197-1.123$ & $0.089^{*}$ \\
Baseline serum magnesium concentrations & 0.025 & $0.000-3.388$ & 0.141 \\
\hline OR The odds rat, Confidncen
\end{tabular}

OR The odds ratio, $C l$ Confidence intervals, BMI Body mass index, $C c r$ Creatinine clearance, ALT Alanine aminotransferase, AST Aspartate aminotransferase *Variables with $P$ value $<0.1$

concentration $(P<0.1$, Table 2$)$. Multivariate regression analysis showed that Ccr $(P=0.000 ; 95 \%$ CI:1.008$1.030)$, whether the loading dose was given $(P=0.038$; 95\% CI:0.117-0.941) and measurement time $(P=0.008$; 95\% CI:0.688-0.947) were independent risk factors for sub-therapeutic blood magnesium concentration (Table 3).

Independent risk factors of continuous variables were analyzed by ROC curve (Table 4). The area under ROC curve of Ccr was 0.715 with the cut-off value of $133 \mathrm{~mL} /$ min. The area under the ROC curve of measurement time was 0.650 with the cut-off value of $2.375 \mathrm{~h}$ (Fig. 1). The results showed that when $\mathrm{Ccr} \geq 133 \mathrm{~mL} / \mathrm{min}$ or the duration of $\mathrm{MgSO}_{4}$ maintenance dose was less than $2.375 \mathrm{~h}$, the blood magnesium concentration was less likely to reach the target range of $1.8-3.0 \mathrm{mmol} / \mathrm{L}$.

\section{Discussion}

The results of this study indicated 52 (55.91\%) patients did not attain therapeutic serum magnesium levels and

Table $\mathbf{3}$ Independent risk factors associated with subtherapeutic blood magnesium concentration

\begin{tabular}{llll}
\hline Variables & OR & $\mathbf{9 5 \%} \mathbf{C l}$ & $\boldsymbol{P}$-value \\
\hline Weight & $/$ & $/$ & 0.467 \\
BMI & $/$ & $/$ & 0.774 \\
Ccr & 1.019 & $1.008 \sim 1.030$ & $0.000^{\Delta}$ \\
Albumin & $/$ & $/$ & 0.516 \\
Measurement time & 0.807 & $0.688 \sim 0.947$ & $0.008^{\triangle}$ \\
Whether the loading dose was given & 0.332 & $0.117 \sim 0.941$ & $0.038^{\triangle}$ \\
\hline
\end{tabular}

OR The odds ratio, $\mathrm{Cl}$ Confidence intervals, BMI Body mass index, $\mathrm{Ccr}$ Creatinine clearance

${ }^{\Delta}$ Statistically significant at $P<0.05$ maternal Ccr, whether the loading dose was given and measurement time were major determinants of attainment of therapeutic serum magnesium concentration.

The elimination of $\mathrm{MgSO}_{4}$ occurs primarily in the kidney, and $\mathrm{PE}$ associated renal damage can result in increased serum magnesium levels [16]. A previous publication showed that the glomerular filtration rate of normal pregnant women was $149 \mathrm{~mL} / \mathrm{min} / 1.73 \mathrm{~m}^{2}$ body surface area [17]. We used Ccr to estimate the glomerular filtration rate, which was calculated by the Cockcroft-Gault equation. From our study, the median (quartile) Ccr of Standard group was $127(98,155) \mathrm{mL} /$ min, lower than normal pregnant women, while Substandard group was $162(132,189) \mathrm{mL} / \mathrm{min}(P<0.05)$. This suggests the reverse association between $\mathrm{Ccr}$ and sub-therapeutic levels. Our study further found that when maternal Ccr $\geq 133 \mathrm{~mL} / \mathrm{min}$, the blood magnesium concentration of severe preeclampisa patients was less likely to reach the target range of $1.8-3.0 \mathrm{mmol} / \mathrm{L}$. We prefer to recommend routine evaluation of serum magnesium levels in augmented renal clearance women because they are at significant risk for being subtherapeutic. It is also necessary to observe closely for signs of toxicity in severe PE cases with delayed renal clearance of $\mathrm{MgSO}_{4}$.

The pharmacokinetic basis of $\mathrm{MgSO}_{4}$ dosing regimens for eclampsia prophylaxis and treatment is not clearly established [11], and there is no report of the time required to reach therapeutic range of serum magnesium concentration after the beginning of administration of maintenance dose in China. However, pharmacodynamics studies showed that with IV $4 \mathrm{~g}$ loading and $2 \mathrm{~g} / \mathrm{h}$ maintenance dose, blood magnesium concentration was twice the baseline value within $30 \mathrm{~min}$, and plateaued at 
Table 4 Results of ROC curve analysis

\begin{tabular}{llllll}
\hline Variables & Area under ROC curve & Youden index & Cut-off & Sensitivity/\% & Specificity/\% \\
\hline Ccr & 0.715 & 0.409 & $\geq 133(\mathrm{~mL} / \mathrm{min})$ & 75.0 & 65.9 \\
Measurement time & 0.650 & 0.323 & $\leq 2.375(\mathrm{~h})$ & 70.7 & 61.5
\end{tabular}

Ccr Creatinine clearance, $R O C$ Receiver operating characteristic

$2-4 \mathrm{~h}$ with minimum fluctuation $[5,11,18]$. At $2 \mathrm{~h}$ after administration, serum magnesium ranged broadly from 1.0-3.5 mmol/L. [16] With our $\mathrm{MgSO}_{4}$ IV infusion regimen $(5 \mathrm{~g}$ loading dose and $1.5 \mathrm{~g} / \mathrm{h}$ maintained for $10 \mathrm{~h}$, or no loading dose and $1.5 \mathrm{~g} / \mathrm{h}$ maintained for $10 \mathrm{~h}$ ), our data suggested that for the duration of $\mathrm{MgSO}_{4}$ maintenance dose of more than $2.375 \mathrm{~h}$, the blood magnesium concentration was more likely to reach the target range of $1.8-3.0 \mathrm{mmol} / \mathrm{L}$.

Our study is the first report on whether the serum magnesium during the maintenance administration of $\mathrm{MgSO}_{4}$ can reach the therapeutic range in patients with severe PE in China. Phuapradit and colleagues [19] reported that when the regimen of their patients with diagnosis of severe $\mathrm{PE}$ were given a $5 \mathrm{~g} \mathrm{MgSO}_{4}$ intravenous bolus infusion and $1 \mathrm{~g} / \mathrm{h}$ continous infusion and continued $24 \mathrm{~h}$ postpartum, only $56.2 \%$ patients had the serum magnesium concentration above the therapeutic level of $2.0-3.5 \mathrm{mmol} / \mathrm{L}$. With our $\mathrm{MgSO}_{4} \mathrm{IV}$ infusion regimen ( $5 \mathrm{~g}$ loading dose and $1.5 \mathrm{~g} / \mathrm{h}$ maintained for 10 $\mathrm{h}$, or no loading dose and $1.5 \mathrm{~g} / \mathrm{h}$ maintained for $10 \mathrm{~h}$ ), only $44.09 \%$ of patients attained therapeutic serum magnesium levels during IV infusion of a maintenance dose, which was similar with Phuapradit and colleagues report [19]. There is few patients attained therapeutic serum magnesium levels, the reason possibly related to lot of patients were not given the loading dose and $\mathrm{MgSO}_{4}$ is excreted by the kidneys. Whether the loading dose was given was confirmed to be one of the risk factors for sub-therapeutic serum magnesium concentration in our study. A total of 61 (65.59\%) patients in the Standard group and Sub-standard group were not given the loading dose, which may be the major reason of low rate of patients attained therapeutic serum magnesium range. During pregnancy, kidney volume increases by up to $30 \%$ [20]. Renal plasma flow and glomerular filtration rate are also increased [21]. The excretion of $\mathrm{MgSO}_{4}$ may increase with the increase of glomerular filtration rate in the patients with severe PE.

It is generally believed that the baseline magnesium serum concentrations complicate the metabolism of $\mathrm{MgSO}_{4}$ [22]. The baseline serum concentrations may have influence on the serum magnesium concentration measured during IV infusion of a maintenance dose. The reported baseline serum magnesium concentrations were consistently $<1 \mathrm{mmol} / \mathrm{L}$ for women with $\mathrm{PE}$ and eclampsia [11]. Also, our study confirmed that the median (quartile) baseline serum magnesium concentration

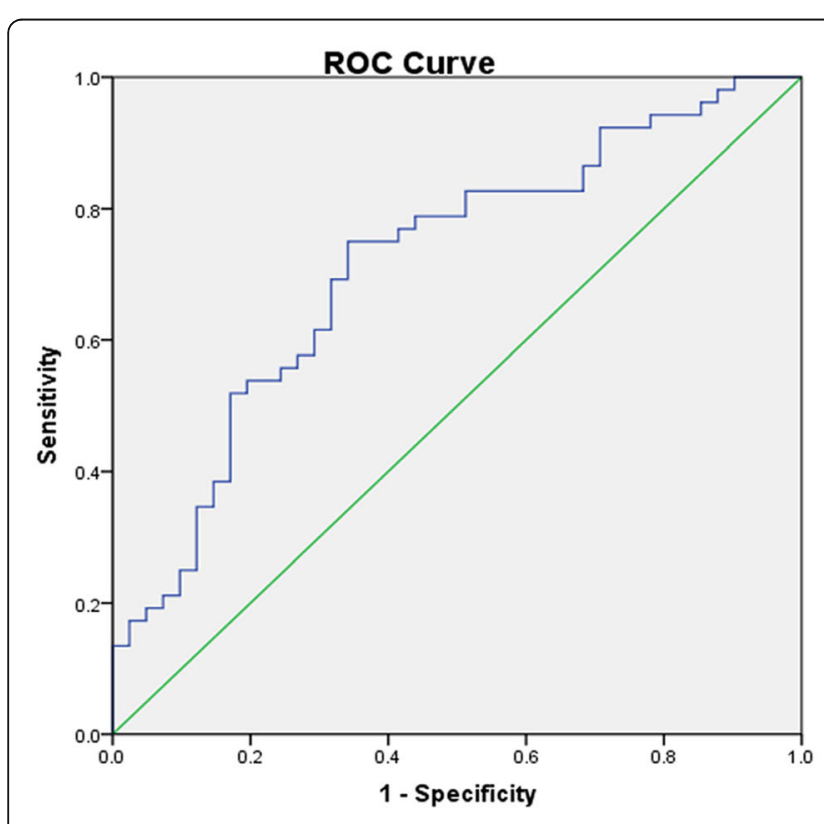

(a)

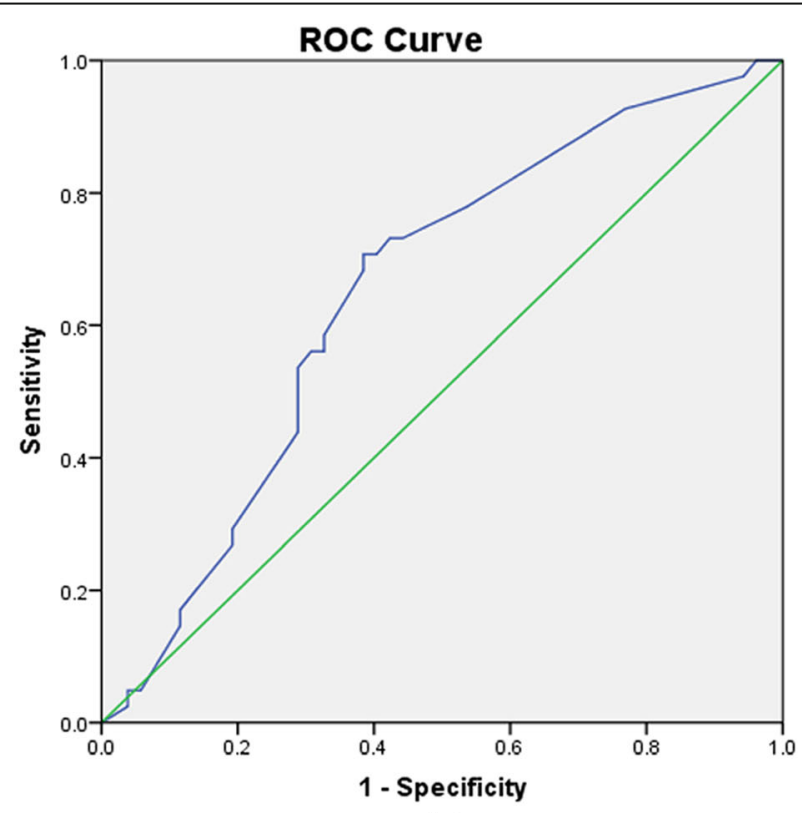

(b)

Fig. 1 a The area under the ROC curve of Ccr was 0.715 with the cut-off value of $133 \mathrm{~mL} / \mathrm{min}$. $\mathbf{b}$ The area under the ROC curve of Measurement time was 0.650 with the cut-off value of $2.375 \mathrm{~h}$ 
of women with severe PE in Standard group was 0.76 $(0.71,0.84)$, while $0.73(0.68,0.81)$ for Sub-standard group. The baseline serum magnesium concentration had no effect on the therapeutic serum magnesium concentration after administration of $\mathrm{MgSO}_{4}$ in our study. However, due to the small sample size of our study, the effect may have not been observed.

Previous studies reported disagreement as to the recommended IV administration dosage and therapeutic levels of $\mathrm{MgSO}_{4}$. Published dose regimens for $\mathrm{MgSO}_{4}$ vary widely, with loading doses of 4-6g intravenously over 20-30 min and maintenance doses of $1-2 \mathrm{~g} / \mathrm{h}$ (and up to $3 \mathrm{~g} / \mathrm{h}$ ) $[8,12]$. The most common $\mathrm{MgSO}_{4}$ regimen is a loading dose of $6 \mathrm{~g}$ intravenously over 15 to $20 \mathrm{~min}$ followed by $2 \mathrm{~g} / \mathrm{h}$ as a continuous infusion [2, 23-25]. A therapeutic range of $2.0-3.5 \mathrm{mmol} / \mathrm{L}$ has been recommended based on retrospective data [9]. However, Chinese guidelines for the diagnosis and treatment of hypertension and preeclampsia in pregnancy recommend the therapeutic serum magnesium level of 1.8-3.0 $\mathrm{mmol} / \mathrm{L}$, with a loading dose $2.5-5 \mathrm{~g}$ and a maintenance dose of $1-2 \mathrm{~g} / \mathrm{h}$ for $6-12 \mathrm{~h}$ [4]. But the guideline does not clearly state that the loading dose needs to be given every day before the maintenance dose of $\mathrm{MgSO}_{4}$ is administered. Therefore, a loading dose of $\mathrm{MgSO}_{4}$ is usually only administered to the patients who begin to receive treatment of $\mathrm{MgSO}_{4}$ for eclampsia prophylaxis on the first day in Chinese clinical practice. Our study found that patients with severe PE who were not given a loading dose were less likely to reach the target serum magnesium range. It has been repeatedly shown that the protocol of $4 \mathrm{~g}$ loading and $2 \mathrm{~g} / \mathrm{h}$ maintenance infusion in preeclampsia-eclampsia patients can attain better therapeutic levels of serum magnesium compared to other protocols with no detectable difference in maternal and neonatal outcomes $[9,26]$. Hence, we may consider recommending that a loading dose be used before the maintenance dose of $\mathrm{MgSO}_{4}$ is administered every time in China.

The association between elevated BMI and subtherapeutic $\mathrm{MgSO}_{4}$ levels was not confirmed in our research, which was inconsistent with previous reports $[16,27,28]$. The reason may be related to the small sample of cases, which lead to the weakening of statistical significance. In addition, maternal BMI is correlated with gestational age, so the effects of these two parameters on serum magnesium levels cannot be clearly differentiated. Our study found there was no significant difference between Standard group and Sub-standard group regarding gestational age, which may result in no significant impact of BMI on serum magnesium levels.

The major strengths of the present study are as following. First, this is the first report on whether the serum magnesium during the maintenance administration of
$\mathrm{MgSO} 4$ reaching the therapeutic range in patients with severe PE in China. Second, the present results are useful to the clinical practice. A loading dose of $\mathrm{MgSO}_{4}$ is recommended to be administered everytime before the maintenance dose to achieve target serum magnesium concentration range of $1.8-3.0 \mathrm{mmol} / \mathrm{L}$.

There are limitations to this retrospective study due to limited clinical data. (1) Its retrospective nature precluded the best assessment methodology. And because of the small sample size, we did not observe a significant difference in efficacy of seizure prevention between the two groups. (2) It was inevitable that some variables were absent because the existing data was collected from medical record retrospectively. Fortunately, most required information in this study was included in the medical records. (3) We excluded the severe PE patients with serious co-morbidities such as hepatic diseases, kidney diseases, etc. The exclusion of these patients may limit our data collection. (4) Including subjects who did not receive a loading dose may dilute findings from those who received a standard approach. Because of the small sample size, the ROC curves generated were not particularly strong for a predictive test. Further prospective cohort studies with a larger sample size are necessary to draw any definitive conclusions on these issues. (5) The minimum effective treatment concentration of $\mathrm{MgSO}_{4}$ for prophylaxis and treatment of severe PE has largely been based on clinical and laboratory observations in earlier studies rather than standard exposure-response studies $[6,12]$.Although some pharmacokinetic studies of $\mathrm{MgSO}_{4}$ administration in preeclamptic women are reported [29-32], there has been no rigorous evaluation of therapeutic serum magnesium concentration [11]. In the future, we will conduct a prospective study on whether patients with severe $\mathrm{PE}$ can achieve effective treatment concentration with $\mathrm{MgSO}_{4}$. Due to the complexity of the use of $\mathrm{MgSO}_{4}$ in the world, we also want to further study the impact of $\mathrm{MgSO}_{4}$ IV infusion regimen with or without loading dose on the blood concentration.

\section{Conclusions}

In conclusion, the incidence of sub-therapeutic serum magnesium concentration during the maintenance administration in Chinese severe PE patients is high and associated with Ccr, whether the loading dose was given, and measurement time. Thus, to achieve targeted therapeutic serum magnesium concentrations, we recommend a loading dose of $\mathrm{MgSO}_{4}$ everytime before, as well as the duration of $\mathrm{MgSO}_{4}$ maintenance dose of more than $2.375 \mathrm{~h}$ for all the patients with severe PE. Women with severe PE and whose Ccr is $\geq 133 \mathrm{~mL} / \mathrm{min}$ are recommended to do routine evaluation of serum magnesium levels. 


\section{Abbreviations}

ALT: Alanine aminotransferase; AST: Aspartate aminotransferase; BMl: Body mass index; Ccr: Creatinine clearance; Cl: Confidence intervals; IV: Intravenous; $\mathrm{MgSO}_{4}$ : Magnesium sulfate; OR: Odds ratio; PE: Preeclampsia; ROC: Receiver operating characteristic; SD: Standard deviation

\section{Acknowledgements}

Not applicable.

\section{Authors' contributions}

Design of the study: JJL, LT, YXY; Data aquisition: RHT, LP, LQC, LPZ; Data analysis: JلL, LT, RHT, YXY; Draft the manuscript: JاL, LT, RHT, YXY; Manuscript revise and final version approval: $Y X Y$. J $J L$ and $L T$ contributed equally to this work. All authors have read and approved the final manuscript.

\section{Funding}

This work was supported by two grants, A201726 and Q2018163, from the Foundation of Jiangsu Pharmaceutical Association of China. Funders had no influence on the design of the study, the data collection and analysis, and the manuscript writing.

\section{Availability of data and materials}

The data of this study is available from the corresponding authors on reasonable request.

\section{Ethics approval and consent to participate}

The present study was approved to collect the clinical data from electronic medical records by the ethics committee of Suzhou Municipal Hospital (K2017037). Since the study was a simple general retrospective study, it was hard to obtain the written informed consent from all participants. The ethics committee approved us to obtain verbal informed consent by telephone from all participants.

\section{Consent for publication}

Not applicable.

\section{Competing interests}

The authors declare that they have no competing interests.

\section{Author details}

${ }^{1}$ Department of Pharmacy, The Affiliated Suzhou Hospital of Nanjing Medical University, Suzhou Municipal Hospital, Suzhou 215002, Jiangsu, China. ${ }^{2}$ School of Medicine, Xuzhou Medical University, Xuzhou 221000, Jiangsu, China. ${ }^{3}$ Department of Obstetrics, The Affiliated Suzhou Hospital of Nanjing Medical University, Suzhou Municipal Hospital, Suzhou 215002, Jiangsu, China.

Received: 2 April 2020 Accepted: 23 September 2020 Published online: 01 October 2020

\section{References}

1. Norwitz ER, Repke JT. Preeclampsia prevention and management. J Soc Gynecol Investig. 2000;7(1):21-36

2. Sibai BM. Magnesium sulfate prophylaxis in preeclampsia: lessons learned from recent trials. Am J Obstet Gynecol. 2004;190(6):1520-6.

3. American College of Obstetricians and Gynecologists, Task Force on Hypertension. Hypertension in pregnancy. Report of the American college of obstetricians and gynecologists' task force on hypertension in pregnancy. Obstet Gynecol. 2013;122(5):1122-31.

4. Hypertensive Disorders in Pregnancy Subgroup, Chinese Society of Obstetrics and Gynecology, Chinese Medical Association. Diagnosis and treatment of hypertension and pre-eclampsia in pregnancy: a clinical practice guideline in China (2015). Chin J Obstet Gynecol. 2015;50(10):721-8. https://doi.org/10.3760/cma.j.issn.0529-567X.2015.10.001.

5. Sibai BM, Graham JM, McCubbin JH. A comparison of intravenous and intramuscular magnesium sulfate regimens in preeclampsia. Am J Obstet Gynecol. 1984;150(6):728-33.

6. Chesley LC, Tepper I. Levels of magnesium attained in magnesium sulfate therapy for preeclampsia and Eclampsia. Surg Clin North Am. 1957;37(2): 353-67
7. Eastman NJ, Steptoe PP. The Management of pre-eclampsia. Can Med Assoc J. 1945:52(6):562-8.

8. American College of Obstetricians and Gynecologists (ACOG). ACOG practice bulletin no. 202 summary: gestational hypertension and preeclampsia. Obstet Gynecol. 2019;133(1):211-4.

9. Sibai BM, Lipshitz J, Anderson GD, Dilts PV Jr. Reassessment of intravenous $\mathrm{MgSO}_{4}$ therapy in preeclampsia-Eclampsia. Obstet Gynecol. 1981;57(2):199202.

10. Lu JF, Nightingale CH. Magnesium sulfate in Eclampsia and pre-eclampsia: pharmacokinetic principles. Clin Pharmacokinet. 2000;38(4):305-14.

11. Okusanya BO, Oladapo OT, Long Q, Lumbiganon P, Carroli G, Qureshi Z, Duley L, Souza JP, Gülmezoglu AM. Clinical pharmacokinetic properties of magnesium Sulphate in women with pre-eclampsia and Eclampsia. BJOG. 2016;123(3):356-66.

12. Pritchard JA. The use of the magnesium ion in the Management of Eclamptogenic Toxemias. Surg Gynecol Obstet. 1955;100(2):131-40.

13. Pascoal Ana CF, Katz L, Pinto MH, Santos CA, Braga Luana CO, Maia SB, Amorim Melania MR. Serum magnesium levels during magnesium sulfate infusion at 1 gram/hour versus 2 grams/hour as a maintenance dose to prevent Eclampsia in women with severe preeclampsia: a randomized clinical trial. Medicine (Baltimore). 2019:98(32):e16779.

14. Chesley LC, Tepper I. Plasma levels of magnesium attained in magnesium sulfate therapy for preeclampsia and eclampsia. Surg Clin North Am. 1957; 37(2):353-67.

15. Magpie Trial Follow-Up Study Collaborative Group. The magpie trial: a randomised trial comparing magnesium sulphate with placebo for preeclampsia. Outcome for women at 2 years. BJOG. 2007;114(3):300-9.

16. Leetheeragul J, Boriboonhirunsarn D, Reesukumal K, Srisaimanee N, Horrasith S, Wataganara T. A retrospective review of on-admission factors on attainment of therapeutic serum concentrations of magnesium sulfate in women treated for a diagnosis of preeclampsia. J Matern Fetal Neonatal Med. 2020;33(2):258-66.

17. Hladunewich MA, Myers BD, Derby GC, Blouch KL, Druzin ML, Deen WM, Naimark DM, Lafayette RA. Course of Preeclamptic glomerular injury after delivery. Am J Physiol Renal Physiol. 2008;294(3):F614-20.

18. Taber EB, Tan L, Chao CR, Beall MH, Ross MG. Pharmacokinetics of ionized versus Total magnesium in subjects with preterm labor and preeclampsia. Am J Obstet Gynecol. 2002;186(5):1017-21.

19. Phuapradit W, Saropala N, Haruvasin S, Thuvasethakul P. Serum level of magnesium attained in magnesium sulfate therapy for severe preeclampsia. Asia Oceania J Obstet Gynaecol. 1993;19(4):387-90.

20. Roy C, Saussine C, Jahn C, Le Bras Y, Steichen G, Delepaul B, Campos M, Chambron J, Jacqmin D. Fast imaging MR assessment of ureterohydronephrosis during pregnancy. Magn Reson Imaging. 1995;13(6): 767-72.

21. Odutayo A, Hladunewich M. Obstetric nephrology: renal hemodynamic and metabolic physiology in normal pregnancy. Clin J Am Soc Nephrol. 2012; 7(12):2073-80

22. Chuan FS, Charles BG, Boyle RK, Rasiah RL. Population pharmacokinetics of magnesium in preeclampsia. Am J Obstet Gynecol. 2001;185(3):593-9.

23. Witlin AG, Sibai BM. Magnesium sulfate therapy in preeclampsia and eclampsia. Obstet Gynecol. 1998;92(5):883-9.

24. Alexander JM, Mclntire DD, Leveno KJ, Cunningham FG. Selective magnesium sulfate prophylaxis for the prevention of eclampsia in women with gestational hypertension. Obstet Gynecol. 2006:108(4):826-32.

25. Cunningham FG, Leveno KJ, Bloom SL, Hauth JC, Rouse DJ, Spong CY. Williams obstetrics. 23rd ed. New York: McGraw Hill; 2010. p. 706-56.

26. Charoenvidhya D, Manotaya S. Magnesium sulfate maintenance infusion in women with preeclampsia: a randomized comparison between 2 gram per hour and 1 gram per hour. J Med Assoc Thail. 2013;96(4):395-8.

27. Dayicioglu V, Sahinoglu Z, Kol E, Kucukbas M. The use of standard dose of magnesium Sulphate in prophylaxis of Eclamptic seizures: do body mass index alterations have any effect on success? Hypertens Pregnancy. 2003; 22(3):257-65.

28. Brookfield KF, Su F, Elkomy MH, Drover DR, Lyell DJ, Carvalho B. Pharmacokinetics and placental transfer of magnesium sulfate in pregnant women. Am J Obstet Gynecol. 2016;214(6):731.e1-9.

29. Salinger DH, Mundle S, Regi A, Bracken H, Winikoff B, Vicini P, Easterling T. Magnesium sulphate for prevention of eclampsia: are intramuscular and intravenous regimens equivalent? a population pharmacokinetic study. BJOG. 2013;120(7):894-900. 
30. Easterling T, Hebert M, Bracken H, Darwish E, Ramadan MC, Shaarawy S, Charles D, Abdel-Aziz T, Nasr AS, Safwal SM, Winikoff B. A randomized trial comparing the pharmacology of magnesium sulfate when used to treat severe preeclampsia with serial intravenous boluses versus a continuous intravenous infusion. BMC Pregnancy Childbirth. 2018;18(1):290.

31. Du L, Wenning LA, Carvalho B, Duley L, Brookfield KF, Witjes H, Greef RD, Lumbiganon P, Titapant V, Kongwattanakul K, Long Q, Sangkomkamhang US, Gülmezoglu AM, Oladapo OT. Alternative magnesium sulfate dosing regimens for women with preeclampsia: a population pharmacokinetic exposure-response modeling and simulation study. J Clin Pharmacol. 2019; 59(11):1519-26.

32. Du L, Wenning L, Migoya E, Xu Y, Carvalho B, Brookfield K, Witjes H, Greef RD, Lumbiganon P, Sangkomkamhang U, Titapant V, Duley L, Long Q, Oladapo OT. Population pharmacokinetic modeling to evaluate standard magnesium sulfate treatments and alternative dosing regimens for women with preeclampsia. J Clin Pharmacol. 2019;59(3):374-85.

\section{Publisher's Note}

Springer Nature remains neutral with regard to jurisdictional claims in published maps and institutional affiliations.

Ready to submit your research? Choose BMC and benefit from:

- fast, convenient online submission

- thorough peer review by experienced researchers in your field

- rapid publication on acceptance

- support for research data, including large and complex data types

- gold Open Access which fosters wider collaboration and increased citations

- maximum visibility for your research: over $100 \mathrm{M}$ website views per year

At BMC, research is always in progress.

Learn more biomedcentral.com/submissions 